\title{
Endonasal endoscopic sinus surgery with rhinobasis resection due to esthesioneuroblastoma: case report.
}

\author{
Karen Dzhambazov ${ }^{1}$, Hristo Zheliazkov ${ }^{2}$, Georgi Stoyanov ${ }^{3}$, Petar Rouev ${ }^{3}$, Nikoleta Traykova ${ }^{4}$, Anna \\ Mihaylova $^{5}$, Penka Petleshkova ${ }^{5}$, Stoyan Markov $^{1 *}$ \\ ${ }^{1}$ ENT Department, UMHAT “St. George” Plovdiv, Bulgaria \\ ${ }^{2}$ Department of Neurosurgery, UMHAT "St. George" Plovdiv, Bulgaria \\ ${ }^{3}$ ENT Department, MHAT “Trakia” Stara Zagora, Bulgaria \\ ${ }^{4}$ Department of Radiology, UMHAT “St. George” Plovdiv, Bulgaria \\ ${ }^{5}$ Medical College, Medical University of Plovdiv, Bulgaria
}

\begin{abstract}
Aim: Esthesionevroblastoma is a rare malignant neuroectodermal tumor that begins development of neuroepithelial cells of the olfactory membrane. Therefore the biology of the tumor, surgery is a method of choice. Endoscopic transnasal method with craniobasal resection is favorable alternative to more invasive surgical methods in a rigorous assessment of patients. Our aim is to describe the first case in the country operated endonasal with typical clinical and histopathological findings of olfactory neuroblastoma, and to discuss opportunities for radical surgery by endoscopic endonasal sinus surgery. Material and methods: We present a patient with nasal obstruction, epistaxis, smell disturbance, headache and eye symptoms.

Results: Single step transnasal endoscopic resection with craniektomia, then undergoes postoperative radiotherapy is made on the patient. One year after surgery, no clinical, endoscopic and radiologic evidence of disease recurrence.

Conclusion: Esthesionevroblastoma is a rare malignant tumor that untypical because its initial symptoms are often diagnosed at later stages. Early detection and timely performed treatment is important moment for the prognosis.
\end{abstract}

Keywords: Esthesionevroblastoma, Endoscopic sinus surgery, Endoscopic resection, Transnasal craniectomia.

Accepted on January 18, 2019

\section{Introduction}

Esthesionevroblastoma is called with different names-olfactory neuroblastoma, olfactory esthesioneuroepiteloioma, olfactory esthesioneurinoma, esthesioneurocitoma, neuroendocrine carcinoma, has been described for the first time from Berger and Luc in 1924 year in the French and from Schall and Linback in 1951 year in the American literature [1-3]. Till now about 1000 cases have been described [4]. We did not found a separate publication in the Bulgarian special literature and periodic $[5,6]$.

In the structure of the oncological illness the olfactory neuroblastoma presents itself as a rare tumor $2-6 \%$ of the endonasal neoplasms and $0.3 \%$ of those from the upper aero digestive tract $[5,7]$. The disease olfactory neuroblastoma has dual age peak in the second/11-20/ and sixth/51-60/decade of life and affects equally both sexes [7-11].

\section{Case}

We present 53-year-old patient with left side nasal obstruction, periodic nasal bleeding, decreasing of the olfaction, headache and pain in the left eye. The complaints of difficult nose breathing are one year long, for a few weeks the left eye glowed red and oozing. Rhinoscopy: tumor formation filling the left nasal cavity pushing vastly the septum to the right, easily bleeding when it touched. Exophthalm of the left eye and hyperemia of the conjunctiva. Neck-there are no pathologically enlarged lymph nodules in palpation. CT of the nose and paranasal cavities-left maxillary sinus, ethmoid cells, sphenoid and frontal sinuses are filled with soft tissue formation with destruction of the nearby bone structures, advancing to the medial pare of the left orbital cavity (Figures $1 \mathrm{a}$ and $1 \mathrm{~b})$. EMR showed dura matter infiltration without intracranial space penetration. A biopsy was taken in MHAT "Trakia", Stara Zagora with histological result: olfactory neuroblastoma III $^{\text {th }}$ degree with positive expression for 
sinaptophisin, focal positive for S-100 protein and negative reaction for cytokeratin and $\mathrm{CD} 45$. The disease is stage $\mathrm{C}$ up to Kadish classification and T4N0M0 according TNM. The stage of differentiation is grade III. After oncology committee discussion a decision was made for surgical treatment and postoperative radiotherapy and the patient was directed to the Integration center for trauma and tumor treatment in UMHAT "St. George" Plovdiv by a team consisting of ENT specialist and neurosurgeon (Figure 2). Surgical steps: (1) Under general anesthesia using endoscope a flap by Hadad was made [12-15] on the right with right side pansinusotomy. (2) Septum resection followed by step by step centripetal extirpation under endoscopic control from the left maxillary sinus, extirpation of the tumor part which was penetrating through the left ethmoid cells towards orbit after that the scull base was reached under subperiostally. Radical extirpation of the tumor was made from the sphenoid and frontal sinuses and Draf III drainage type of sphenoidal and frontal sinuses was made (3). After ethmoid arteries cauterization, the skull base was resected from the sphenoid sinus to the frontal sinuses. (4) For total tumor removal the skull base durra was resected and after that it was separated from the subarachnoid space and removed together with crista galli. (5) This was followed by closure of the durra matter and skull base defects with fascia lata, a piece of that fascia was led to the base and it's ends was tucked over the dura, it was packed with muscle and glued with tissue glue, the closure was strengthened at the end with the flap from the septum, a tight nasal tampon was made. Hematoma in the bulb of the right eye was found during the operation and lateral cantotomy was made as well as cauterization of the retracted towards orbit ethmoid artery (Figure 3).

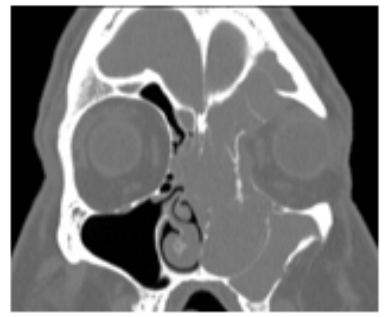

(a)

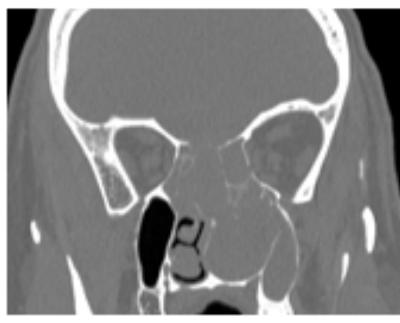

(b)
Figure 1. (a) \& (b): Preoperative CT scan of the paranasal sinuses.

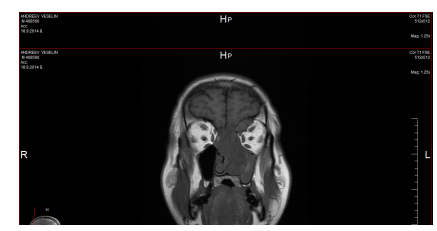

Figure 2. Preoperative MRI of the paranasal sinuses.

The post-operative period was without complications, without bleeding a normal vision of the right eye was detected, a consultation with ophthalmologist was made-ophthalmoscopyleft eye papilla pale with total atrophy, vessels, macula, retinanormal. The hematoma of the right orbit gradually faded away. The control endoscopic exam at the $21^{\text {st }}$ day after the operation do not discovered residual tumor formation; the scull base plastic is unimpaired without cerebrospinal fluid rhinorrhea evidences. Postoperative radiotherapy was administrated with X-ray linear accelerator in the nasal cavity area, frontal, maxillary and ethmoid sinuses on the left 40 Gray draining the tolerance for the right eye. At the sixth month after the radiotherapy an endonasal endoscopic exam was made (Figure 4a), a lot of scabs were removed from the operative cavity, but no signs of blastoma growth presentation were found (Figure $4 \mathrm{~b}$ ). The CT investigation of the nose and nasal cavities one year after the operation do not showed any data for recurrences (Figures 5a and 5b).

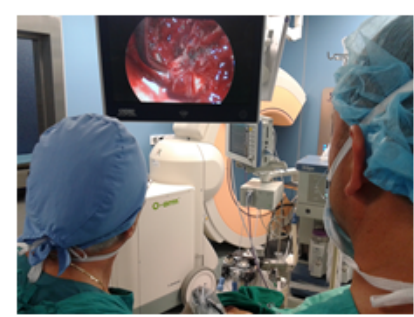

(a)

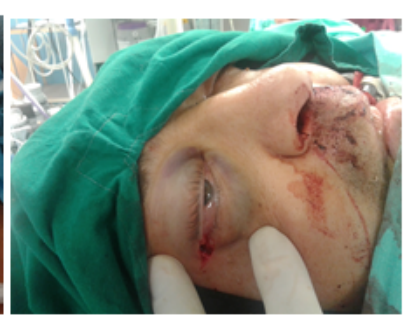

(b)
Figure 3. (a) \& (b). Intraoperative-ENT team and right side craniotomy.

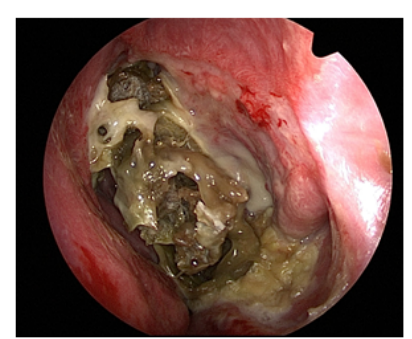

(a)

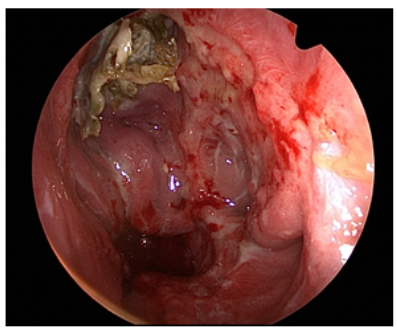

(b)
Figure 4. (a) \& (b): Postoperative endoscopy at the $6^{\text {th }}$ month before the crust removal.

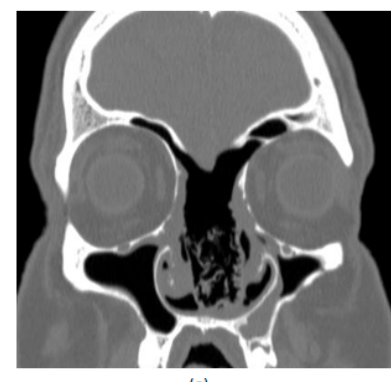

(a)

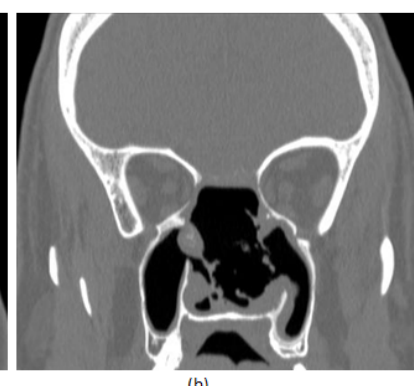

(b)
Figure 5. (a) \& (b): Postoperative CT scan/after FESS.

\section{Discussion}

In the cases with olfactory neuroblastoma the trend points comparatively late diagnosis because of the nonspecific early patient complaints $[2,11,16]$. The most common patient complaints are one side nasal obstruction, nasal bleeding and oozing from the eyes. The olfactory neuroblastoma symptoms can be grouped as nasal (nasal obstruction, nasal bleeding, 
anosmia), neurological (headache, nausea), oral (thrismus), facial (swelling, anesthesia, pain), eye symptoms (oozing, diplopia, poor eye vision), neck symptoms (tumor mass) [17]. The diagnostic algorithm includes image tests, endonasal endoscopy, biopsy and histological verification [11].

The olfactory neuroblastoma morphologic interest is linked not only with the fact that it is a rare tumor, but also because it is a difficult histopathological diagnosis with various histological manifestations which includes a spectrum of different morphologic subtypes [9]. Putting the diagnosis olfactory neuroblastoma requires histological investigation and immunohistochemically verification to specify its histogenetic origin. For immunohistochemically verification and differential diagnosis a special composition of markers is used. The olfactory neuroblastoma is histochemicalli positive for neuron specific endolaze (NSE), S 100, synaptophysin and chromatin or both in 77 to $100 \%$ of cases. Tumor cells are always negative for EMA, desmine, myoglobulin, valentine $[6,16]$. The histological differential diagnosis of olfactory neuroblastoma includes: spinocellular carcinoma, sinunasal carcinoma without differentiation, extra nodal lymphoma, rabdomyosarcoma, malignant melanoma, neuroendocrine carcinoma, extra medullar plasmocytoma, Ewing`s sarcoma, adenoma of the pituitary gland, extra cranial meningioma, mesenchymal chondrosarcoma, granulate sarcoma, adenocarcinoma, metastatic carcinoma [7,16].

The imaging diagnosis takes essential place during the whole period of diagnosing, treatment and dynamic follow up of the patients with olfactory neuroblastoma. CT and MRI are necessary for adequate evaluation of the tumor extension and determining the diagnostic-curative algorithm. The combination CT and MRI is very useful because combining their abilities we can provide the best information about the tumor invasion. CT enables tumor invasion visualization of nasal and paranasal cavities, bone erosions of lamina papyracea and lamina cribrosa. MRI is very useful for identification of tumor dissemination towards the soft tissue zones nearby as orbit, dura and makes possible the intracranial invasion to be seen $[7,8]$.

The technological progress at the image methods led to vast elaboration of the clinical assessment of the disease dissemination. The stage of dissemination/staging/ of the olfactory neuroblastoma is evaluated by TNM and Kadish system.

\section{Clinical classification}

In the clinical practice the staging system suggested by Kadish et al. [18] is taking place. It is according the disease dissemination in three stages A-C [14]. Later on Morita et al. [19] suggested modification of the system consisting of separation of the patients with metastases in the neck lymph nodules or distant metastases in stage D (Table 1).

Table 1. Kadish's classification.

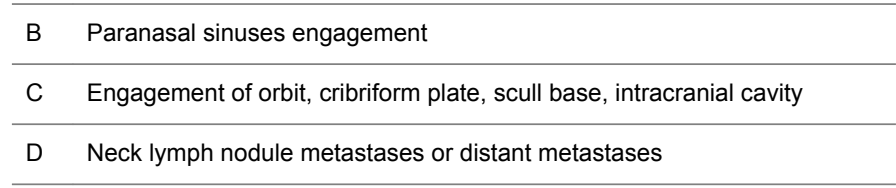

\section{TNM classification}

In 1992 Dulguerov and Calceterra suggested classification based upon the TNM system rules (Table 2) [4,17].

Table 2. TNM paranasal sinus tumor classification.

\begin{tabular}{ll}
\hline T1 & $\begin{array}{l}\text { Tumor in the nasal and/or paranasal cavities with the exception of } \\
\text { sphenoid sinus and upper ethmoid cells }\end{array}$ \\
\hline T2 & Engagement of sphenoidal sinus or cribriform plate erosion \\
\hline T3 & Orbit and frontal scull base fosse engagement \\
\hline T4 & The tumor engages the brain \\
\hline N0 & No neck metastases \\
\hline N1 & Neck metastases \\
\hline M0 & No distant metastases \\
\hline M1 & Distant metastases \\
\hline
\end{tabular}

\section{Malignancy degree}

For malignancy determination/Grading/ the Hyams staging is adopted, in use since1988 year. The classification is based on the stage of differentiation of tumor's histological characteristics. This system divides the disease into four stages from well-differentiated (I grade) to poorly differentiated (IV grade) according to the tumor architecture, the cell pleomorphism, neurofibrillary matrix presence and rosettes, mitotic activity, and presence of necroses and calcifficates [5].

\section{Prognostication factors}

The olfactory neuroblastoma prognosis is usually determinate by a combination of clinical and pathological factors. Factors with negative influence upon prognosis are advanced stage, poorly differentiated tumor, young age, positive for tumor infiltration resection lines, distant metastases [4]. As a prognostic feature tumor invasion in the nearby structures especially brain and orbit worsening the prognosis [11]. Many authors discover that the stage of malignancy by Hyams and Kadish`s staging system are in a great prognostic correlation with the progress of the disease $[4,11,16,20,21]$. The olfactory neuroblastoma treatment includes primary surgical treatment, primary radiotherapy, and combination of both and if it is necessary adjuvant chemotherapy. In cases with local tumor advance and high grade of malignancy an aggressive treatment must be launched using combined treatment models [3].

Golden standard in treatment strategy of Kadish C patients is radical surgical eradication combined with postoperative radiotherapy [12].

A Tumor in the nasal cavity 
The surgical treatment recommendations embrace many operations from the traditional craniofacial resections with different variations to the less invasive endoscopic methods.

The open surgical treatment techniques like combined trans facial or neurosurgical approaches have proven their role through the years for treatment of tumors with anterior scull base fossa engagement. These approaches permit "en block" tumor resection but are related to serious complications/ intracranial bleedings, intracranial infections, orbital complications, cranial nerve injury, cerebrospinal fluid leek, pneumocefalus, infections, lethality up to $5 \%[2,7,11,14,22]$.

The endoscopic surgery progress through the last decades in the surgical techniques as well as the development of the technologies, for example systems for navigation have made the endoscopic trans nasal resections acceptable and effective method in a number of selected cases. Endonasal endoscopic surgery is an alternative for anterior scull base fossa approach using it a lot of disadvantages of the conventional neurosurgical methods are avoided. The choice of surgery technique depends on the tumor size, direction of dissemination and nearby zones engagement [7,9,20].

It must be kept in mind that Kadish $\mathrm{C}$ and D stages are usually treated with open techniques, while the endoscopic techniques are limited for treatment of A and B stages. In spite of that fact many authors support the endonasal endoscopic resection in advanced cases with intradural resection whenever it is necessary, in a condition that the principles of radical surgery are kept and the achieved tumor control results can be compared with that from the conventional surgery. A precise patient selection is necessary during the period before surgery as well as selection of the eligible surgical method for every patient $[7,14,15,23]$. The decision about the most appropriate surgical method must be taken by a team consisting of ENT specialist, neurosurgeon, oncologist, and it must be discussed with the patient. If there are regional lymph nodules metastasis a neck dissection is made, as rule positive lymph nodules are bad prognostic factor for the patients with olfactory neuroblastoma [10]. The role of chemotherapy is discussed in patients with advanced disease, high stage of tumor malignancy, with distant metastases, in case of recurrence $[2,7,10]$.

Periodic clinical examinations, endoscopic endonasal inspection, CT scan and MRI are important for the early detection of recurrences of the disease and metastases [7].

\section{Conclusion}

Olfactory neuroblastoma is a rare malignant tumor which because of its non-specific initial symptoms usually is diagnosed in its advanced stages. Bringing the endoscopic technique into use gives more possibilities for discovering the early forms of the disease, radical surgical treatment, patient's follow up and recurrences identification. According to good medical practice rules the diagnostic and treatment plan in every single patient must be made by a team of specialists. A joint efforts of ENT specialists, neurosurgeons, pathologists, image specialists, radiologists are necessary for improvement the results of the extesioneuroblastoma treatment. The treatment can be only surgery or combination with radiotherapy and chemotherapy.

The advantages of the endoscopic intervention are the smallest tissue trauma and vastly easier postoperative period. This surgical treatment method minimizes patient's trauma from the surgery, improves way of life and gives a chance for good disease control. The technological progress in the field of medical equipment and introduction of new modern diagnostic and surgical methods gave new chances to those patients.

\section{References}

1. Malamov M, Georgiev G. Treatment of tumors of the ears, nose and throat. Med Phys Educ Sofia 1983; 75.

2. Tatagiba M, Samii M, Dankoweit-Timpe E, Aguiar PH, Osterwald L, Babu R, Ostertag H. Esthesioneuroblastomas with intracranial extension. Proliferative potential and management. Arq Neuropsiquiatr 1995; 53: 577-586.

3. Tramacere F, Bambace S. Esthesioneuroblastoma treated with external radiotherapy. Case report. Acta otorhinolaryngologica Italica 2008; 28: 215-217.

4. Sharma S, Sharma M, Johnson M. Esthesioneuroblastoma-a clinicopathologic study and role of DNA topoisomerase alpha. Pathol Oncol Res 2007; 13: 123-129.

5. Platek M, Merzianu M. Improved survival following surgery and radiation therapy for olfactory neuroblastoma: analysis of the SEER database. Rad Oncol 2011; 6: 41.

6. Barnes L. Surgical pathology of the head and neck (3rd Edn.). Informa Healthcare 2008; 728-733.

7. Papacharalampous G, Vlastrarakos P, Chrysovergis A. Olfactory neuroblastoma: towards minimally invasive surgery and multi-madality treatment strategies-an updated critical review of the current literature. JBUON 2012; 18: 557-563.

8. Li C, Yousem DM, Hayden RE, Doty RL. Olfactory neuroblastoma: MR evaluation. AJNR Am J Neuroradiol 1993; 14: 1167-1171.

9. Stamenov B, Tzvetanov P, Simeonova V. Olfactory neuroblastoma: clinical presentation and management. J IMAB 2005; 11: 24-25.

10. Chew Y, Cheong J. Subcutaneous metastasis of olfactory neuroblastoma-an uncommon presentation. Med J Malaysia 2011; 66: 62-63.

11. Castelnuovo P, Bignami M, Delu G. Endonasal endoscopic resection and radiotherapy in olfactory neuroblastoma: our experience. Head Neck 2007; 845-850.

12. Kutin M, Kalinin P, Fomichev D. Experience in the use of autogenic tissues with preservation of blood supply for plastics of skull base defects after endoscopic transsphenoidal interventions. Quest Neurosurg 2012; 2: 42-49. 
13. Hainarosie R, Ceachir O. The use of the composite mucoperichondrial-cartilaginous vascularised septal flap in reconstructive surgery of the skull base defects. Medicina Moderna 2014; 21; 135-138.

14. Greenfield J, Vijay K. Endoskopic endonasal transethmoidal transcribriform transfovea ethmoidalis approach to the anterior cranial fossa and skull base. Neurosurgery 2010; 66: 883-890.

15. Bhatki A, Carrau R. Endonasal surgery of the ventral skull base-endoskopic transcranial surgery. Oral Maxillofacial Surg Clin N Am 2010; 22: 157-168.

16. Shukla RC, Singh PK, Senthil S, Pathak R. Esthesioneuroblastoma: a case report. Nepal Med Coll J 2010; 12: 128-132.

17. Kandakure V, Olfactory Neuroblastoma from ala of nosean unusual presentation. JDMS 2012; 2: 15-19.

18. Kadish S, Goodman M, Wang CC. Olfactory neuroblastoma. A clinical analysis of 17 cases. Cancer 1976;37:1571-1576.

19. Morita A, Ebersold MJ, Olsen KD, Foote RL, Lewis JE, Quast LM. Esthesioneuroblastoma: prognosis and management. Neurosurgery 1993; 32:706-714; discussion 714-705.
20. Po-Wing Yuen A, Fan Y, Fung C. Endoscopic-assisted cranionasal resection of ofactory neuroblastoma. Head et Neck 2005; 488-492.

21. Tural D, Yildiz O, Selcukbiricik F, Ozturk MA, Keles Y, $\mathrm{Oz}$ B, Uzel O, Demir G, Mandel NM. Olfactory neuroblastomas: an experience of 24 years. ISRN Oncol 2011; 2011: 451086.

22. Pasha R, Otolaryngology-head and neck surgery. Clinical Reference Guide (1st Edn.). Singular Thomas learning San Diego 2000; 263-264.

23. Gallia GL, Reh DD, Salmasi V, Blitz AM, Koch W, Ishii M. Endonasal endoscopic resection of esthesioneuroblastoma: the Johns Hopkins Hospital experience and review of the literature. Neurosurg Rev 2011; 34: 465-475.

\section{*Correspondence to}

Stoyan Markov

ENT Department

UMHAT "St. George" Plovdiv

Bulgaria 